\title{
RESPONSABILIDADE PELO FATO DO PRODUTO E DO SERVIÇO
}

\author{
Michele Romero da Costa*
}

RESUMO: Este trabalho tem ênfase em apresentar a espécie de responsabilidade adotada pelo Código Brasileiro de Defesa do Consumidor para os fornecedores de produtos e serviços, qual seja a responsabilidade objetiva, demonstrando uma inovação trazida por este diploma para responsabilidade civil do Direito pátrio. Bem como a sua fundamentação e noções gerais a fim de que se identifiquem as relações em que deve ser o código aplicado, entendidas essas como relações de consumo.

PALAVRAS CHAVE: Responsabilidade objetiva. Consumidor. Fornecedor. Produtos. Serviços.

ABSTRACT: This work has emphasis in presenting the species of responsibility adopted for the Brazilian Code of Defense of the Consumer for the suppliers of products and services, which is the objective responsibility, demonstrating an innovation brought for this diploma for civil liability of the native Right. As well as its general recital and slight knowledge so that if it identifies the relations where it must be the applied code, understood these as consumption relations.

KEY-WORDS: Objective responsibility. Consuming. Supplying. Products. Services.

*Acadêmica do $10^{\circ}$ semestre do curso de Direito da Universidade Federal de Santa Maria, e-mail: michelrc21@ hotmail.com 


\section{INTRODUÇÃO}

As relações de consumo estão presentes no cotidiano de todas as pessoas, já que a crescente massificação do mercado coloca a disposição inúmeros produtos e serviços ao consumidor que, devido a evolução tecnológica e cultural do País, substituiu a economia de subsistência por uma sociedade de consumo. Faz-se, portanto, necessário comprar produtos para o consumo e contratar serviços em geral.

Com base na pesquisa bibliográfica, que foi realizada, procurou-se analisar na primeira parte do trabalho a fundamentação da promulgação do Código Brasileiro de Defesa do Consumidor, esta baseada na Constituição Federal de 1988 e na necessidade da intervenção do Estado a fim de reequilibrar a relação entre o fornecedor e o consumidor, aja vista a posição de vulnerabilidade em que este se encontra. Posteriormente, fez-se uma abordagem geral dos conceitos de consumidor, fornecedor, produtos e serviços que o código utilizou para definir a relação de consumo.

$\mathrm{Na}$ segunda parte da pesquisa, objetivou-se explorar a responsabilidade objetiva adotada pelo diploma legal, a qual fora um grande avanço para o Direito brasileiro na medida em que substituiu de vez a responsabilidade subjetiva antes adotada pelo Código Civil de 1916 para as relações consumistas. Analisou-se, na seqüência, a responsabilidade objetiva dos fornecedores de produtos e serviços, sua aplicação e suas excludentes.

Com isso, objetiva-se demonstrar a importância que o Código de Defesa do Consumidor tem para as relações cotidianas, pois se está, a todo o momento, comprando e contratando serviços. E diante dessa situação, existe a necessidade de tutela do consumidor fazendo-se respeitar a sua dignidade, segurança, saúde e promovendo a melhoria da sua qualidade de vida.

\section{CÓDIGO BRASILEIRO DE DEFESA DO CONSUMIDOR}

\subsection{Fundamentação do código de defesa do consumidor}

O Código de Defesa do Consumidor, Lei $n^{\circ}$ 8.078, de 11-09-1990 (CDC) representa uma importante evolução na responsabilidade civil do direito pátrio. Trata-se de um diploma legal moderno, no qual grande parte de seus princípios são inovadores, bem como coerente e homogêneo, o que possibilitou sua autonomia. O CDC foi consagrado como um micro sistema jurídico de caráter interdisciplinar, vez que se relaciona com outros ramos do Direito, atualizando-os e fornecendo-lhes novos rumos a serem 
seguidos. E por outro lado, multidisciplinar por trata de questões que fazem parte do Direito Constitucional, Penal, Civil, Processual Penal e Civil, Administrativo, tendo como principal objetivo à tutela do consumidor vulnerável frente ao fornecedor.

A promulgação desse novel diploma legal se deve, como bem se abstrai do seu art. $1^{o}$, a preceito constitucional expresso. Assim, mostra-se evidente a preocupação do legislador constitucional em proteger a parte hipossuficiente na relação de consumo, qual seja o consumidor. Desse modo, tem-se primeiramente no art.5 $5^{o}$, inc. XXXII da Constituição Federal que "o Estado proverá, na forma da lei, a defesa do consumidor".

$\mathrm{O}$ art. $170^{\circ}$ da carta constitucional dispõe que "A ordem econômica, fundada na valorização do trabalho humano e na livre iniciativa, tem por fim assegurar a todos existência digna, conforme os ditames da justiça social”, desde que observados determinados princípios, dentre os quais se encontra, no inc. V, a defesa do consumidor.

Essa preocupação do legislador com a defesa do consumidor é também encontrada no art. $48^{\circ}$ do Ato das Disposições Constitucionais Transitórias, na qual se asseverava que o Congresso Nacional deveria elaborar o Código de Defesa do Consumidor dentro de cento e vinte dias da promulgação da Constituição Federal. Prazo esse muito ultrapassado quando da promulgação do Código de Defesa do Consumidor em 11 de setembro de 1990.

Diante disso, a fim de buscar o equilíbrio nas relações de consumo, o código do consumidor tem no "interesse social" um de seus princípios, visando resgatar os consumidores da marginalidade tanto em face do poder econômico, quanto em dotá-los dos instrumentos adequados para o acesso à justiça de forma individual ou coletiva.

\subsection{Conceitos: do consumidor, do fornecedor, do produto e do serviço}

A fim de estudar a responsabilidade civil no Código de Defesa do Consumidor torna-se indispensável ter em mente alguns conceitos adotados por este diploma legal.

Primeiramente tem-se a denominação de consumidor, o qual, consoante o art. $2^{o}$ do CDC, é considerado "toda pessoa física ou jurídica que adquire ou utiliza produto ou serviço como destinatário final”. Esse conceito tem caráter exclusivamente econômico, já que considera apenas o indivíduo que no mercado de consumo adquire ou utiliza produtos e serviços com vistas a satisfazer suas necessidades e não com interesse em desenvolver atividade negocial. Inovando, o código considera-se consumidor tanto a pessoa natural quanto à pessoa jurídica. Diante desse conceito, o 
doutrinador Salvo de Silvio Venosa (2002:146), assim como outros, entende que além das pessoas jurídicas, devem ser considerados consumidores também as entidades com personificação anômala ou chamados entes despersonalizados, como o espólio, a massa falida e o condômino.

É inovador o conceito supra referido quando inclui a pessoa jurídica na definição de consumidor, pois na legislação européia unificada, por exemplo, apenas a pessoa natural é admitida como protegida pela lei. Assim, é considerado consumidor a pessoa jurídica que utiliza ou adquire bens ou serviços para seu uso, sem, no entanto, incorpora-los a outros ou revende-los, colocando-se na mesma posição e contexto de vulnerabilidade nas relações de consumo ${ }^{1}$.

O parágrafo único do art. $2^{\circ}$ do CDC equipara a consumidor "a coletividade de pessoas, ainda que indetermináveis, que haja intervindo na relação de consumo”. Assim, considera-se potenciais consumidores a universalidade, o conjunto deles, grupos, classes ou categorias deles, ainda que indeterminados e como bem se abstrai da referida norma, desde que estejam relacionados a um produto ou serviço.

Ainda o art. $17^{\circ}$, dispõe que "para os efeitos dessa seção, equiparam-se aos consumidores todas as vítimas do evento". Nesse dispositivo busca-se abranger aquelas pessoas que não participaram da relação de consumo, mas que de alguma forma, seja no patrimônio ou na sua integridade física, foram atingidas pelo acidente de consumo, sendo, portanto, vítimas do mesmo.

Por fim, podem se referir duas grandes correntes de tendências do consumerismo: a finalista e a maximalista. A primeira entende que consumidor é aquele não profissional, que adquire ou utiliza produtos ou serviços com vistas ao uso próprio e de sua família. Já para os maximalista, mais adaptados aos objetivos do Código, o dispositivo deve ser interpretado da forma mais extensiva possível, a fim de que alcance não só os consumidores não profissionais, mas o maior número possível de relações no mercado de consumo.

É nesse contexto das relações de consumo que se encontram os "interesses difusos" e os "interesses coletivos". Aqueles têm como característica a pluralidade de titulares, em número indeterminado e indeterminável, bem como a indivisibilidade do objeto, cuja satisfação aproveita a todos, e cuja postergação a todos prejudica ${ }^{2}$. Ainda, segundo Filomeno (1999, p.37),

\footnotetext{
${ }^{1}$ Sílvio de Salvo Venosa,Rresponsabilidade Civil, São Paulo, Atlas S.A., 2002, p. 146.

${ }^{2}$ Moreira apud Filomeno, Código Brasileiro de Defesa do Consumidor Comentado. 6. ed Rio de Janeiro: Forense Universitária, 1999 , p.50.
} 
são interesses difusos os interesses dos destinatários de mensagens publicitárias enganosas ou tendentes a ver inibida a atividade publicitária ou a serem ressarcidos em face do dano econômico imediato pela aquisição de produtos com qualidade inferior àquela prometida, e assim por diante.

Enquanto que os "interesses coletivos", embora igualmente indivisíveis, são relativos a um número determinado de titulares, quais sejam, grupos, classes de pessoas ou categoria ligadas conjuntamente ou à parte contraria através de uma relação jurídica. Já os "interesses individuais homogêneos de origem comum" são interesses ou direitos individuais tratados de forma coletiva.

Quanto aos fornecedores, o art. $3^{\circ}$ do CDC define-os como sendo "toda pessoa física ou jurídica, pública ou privada, nacional ou estrangeira, bem como os entes despersonalizados, que desenvolvem atividades de produção, montagem, criação, construção, transformação, importação, exportação, distribuição, ou comercialização de produtos ou prestação de serviços". A definição de fornecedor no Código de Defesa do Consumidor é bem abrangente e não deve ser considerada taxativa, pois, são incluídas nesse conceito todas aquelas entidades que desempenham as funções estabelecidas no artigo transcrito. A seqüência de fornecedores tem responsabilidade solidária e, portanto, direito de atuarem na via regressiva.

O fornecedor pessoa física é aquele que oferta no mercado de consumo produtos e serviços, desempenhando atividade mercantil ou civil e de forma habitual. Da mesma forma a pessoa jurídica, com o diferencial de que se apresenta como associação mercantil ou civil. Quanto ao fornecedor Público ou Privado, temos no primeiro o próprio Poder Público representado por si, pelas empresas públicas ou pelas concessionárias de serviço.

Além do fornecedor nacional, alcançam o dispositivo os fornecedores estrangeiros, e nesse caso o importador é responsabilizado por eventuais danos ou reparos, podendo voltar-se regressivamente contra o exportador. São considerados também fornecedores, os "entes despersonalizados", entendidos como aquelas entidades que, sem personalidade jurídica, exercem atividade produtiva de bens e serviços.

Por fim, a definição de serviço e produto. Este é considerado como "qualquer bem móvel ou imóvel, material ou imaterial" ( $\left.\operatorname{art} .3^{\circ}, \S 1^{\circ}\right)$ que seja o objeto da relação de consumo e que tenha a finalidade de satisfazer uma necessidade do consumidor final. Serviço é definido como atividades remuneradas fornecidas no mercado de consumo, 
incluindo as de natureza bancária, financeira, de crédito e securitária, com exceção das relações de caráter trabalhistas.

\subsection{A VULNERABILIDADE DO CONSUMIDOR}

Não há que se discutir que o consumidor é o elo mais fraco na relação de consumo. Isso se explica pelos novos modelos de associação do séc. $\mathrm{XX}$, como os monopólios e os oligopólios, pelo domínio do crédito e do marketing, pelo crescente número de produtos e serviços colocados no mercado sem as devidas informações sobre a qualidade, preço, riscos, manutenção e outras características fundamentais; além é claro, do inegável desequilíbrio econômico.

E é nesse âmbito de hipossuficiência do consumidor que se torna imprescindível à atuação do Estado, como bem assevera Grinover e Beijamin $(1999, p .6)$ "nas suas três esferas: o Legislativo criando as normas jurídicas de consumo; o Executivo, implementando-as; e o Judiciário, dirimindo os conflitos decorrentes de esforços de formulação e de implementação”. Desse modo, toda legislação de proteção ao consumidor tem como objetivo reequilibrar e harmonizar as "relações de consumo". É a chamada "Política Nacional de Relações de Consumo", a qual, segundo Filomeno (1999, p.53),

visa exatamente à harmonia das sobreditas" relações de consumo“, porquanto, se por um lado efetivamente se preocupa com o atendimento das necessidades básicas dos consumidores (isto é, respeito à sua dignidade, saúde, segurança e aos seus interesses econômicos, almejando-se a melhoria de sua qualidade de vida), por outro visa igualmente à paz daquelas, para tanto atendidos certos requisitos" e dentre estes "se destacam as boas relações comerciais, a proteção da livre concorrência, do livre mercado, da tutela das marcas e patentes, inventos e processos industriais, programas de qualidade e produtividade, enfim, uma política que diz respeito ao mais perfeito possível relacionamento entre consumidores -todos nos em ultima análise, em menor ou em maior grau- e os fornecedores.

Assim, são direitos básicos do consumidor a facilitação de seu acesso aos instrumentos de defesa, como os PROCONS ou, quando estes não existem, as Promotorias de Justiça, os Juizados Especiais Cíveis, Defensorias Públicas e outros; o estabelecimento da responsabilidade objetiva, aliada a inversão do ônus da prova. Têm- 
se ainda, como um meio de dirimir os conflitos e como uma estratégia de marketing, os canais abertos de contato direto oferecidos pelos fornecedores, bem como órgãos tais como o INMETRO (Instituto Nacional de Metrologia, Normatização e Qualidade Industrial) e o ISSO 9000 a fim de verificar a garantia dos produtos e serviços com padrões adequados de qualidade, segurança, durabilidade e desempenho. ${ }^{3}$

\section{DA RELAÇÃO DE CONSUMO E DE RESPONSABILIDADE}

\subsection{Da responsabilidade subjetiva para a responsabilidade objetiva}

A Revolução Industrial e a Tecnológica são responsáveis pela produção em massa, a qual gerou a distribuição em massa, através das redes de mercados e hipermercados, que por sua vez produziram o consumo em massa. Esta a sociedade consumista em que vivemos. Antes do advento da Lei $n^{o}$ 8078/90, a responsabilidade do fornecedor era regida pelo art. 156 (art. 189 do CC/02) do Código Civil de 1916, onde a responsabilidade era e continua sendo subjetiva. Portanto, cabia ao consumidor lesado o ônus de provar a culpa do demandado. Ainda, consoante o art. $178^{\circ}, \$ 2^{\circ}$ do CC de 1916 (art.441 ${ }^{\circ}$ ss) ficava sujeito ao prazo dos vícios redibitórios ${ }^{4}$ de 15 dias a contar da data da tradição para as coisas móveis. Além disso, a vítima deveria ingressar com a ação contra o fabricante no local de sua sede, o que pela dimensão do nosso país tornava-se de difícil efetivação. Era, ainda, comum não se saber contra quem ingressar com a ação, se contra o fabricante estrangeiro, o importador ou o comerciante. $^{5}$

A lei $\mathrm{n}^{\circ} 8.078$ foi concebida a fim de solucionar essas divergências, harmonizar e proteger a parte hipossuficiente dessa relação de consumo, a qual tem no pólo ativo da relação o fornecedor e no pólo passivo o consumidor. Para tanto, a partir da promulgação da referida Lei, a responsabilidade do fornecedor passa a ser objetiva, com a possibilidade da inversão do ônus da prova. Essa foi uma grande evolução para o Direito Brasileiro.

A colocação de bens e serviços no mercado de consumo suscita a geração da relação de responsabilidade, a qual se divide em responsabilidade extracontratual, que se origina da violação dos direitos tutelados pela ordem jurídica; e responsabilidade contratual, a qual sobrevém do inadimplemento contratual; aqui, é interessante lembrar

\footnotetext{
${ }_{3}^{3}$ FILOMENO, José Geraldo Brito. Código Brasileiro de Defesa do Consumidor. 6.ed. Rio de Janeiro: Forense Universitária, 1999.p.55.

${ }^{4}$ Todo defeito oculto da coisa, que a torna imprópria para o uso a que se destina, ou lhe diminua consideravelmente o valor.

${ }^{5}$ Venosa, Sílvio de Salvo. Responsabilidade Civil. 2. ed. São Paulo: Atlas, 2002. p. 149.
} 
que o código do consumidor não faz essa distinção. Nesse contexto, invertem-se os pólos, pois, com o intuito de reparar os vícios do produto ou do serviço, o consumidor passa a figurar no pólo ativo da relação de responsabilidade e o fornecedor no pólo passivo.

Diante disso, código em comento traz duas modalidades de responsabilidade, quais sejam: "Da Responsabilidade por Vício do Produto e do Serviço" e "Da Responsabilidade pelo Fato do Produto e do Serviço". A primeira é positivada na Seção III, nos arts. 18 a 25 do CDC, a qual trata dos vícios ou defeitos de adequação. Nessa hipótese encontram-se os produtos ou serviços defeituosos que não correspondem à legítima expectativa do consumidor quanto a sua utilização e fruição; por exemplo, quando se compra uma roupa com defeito de numeração, o produto é inadequado, mas não gera insegurança e, nesse caso, observa-se que o defeito costuma aparecer na fase inaugural do consumo.

A responsabilidade pelo fato do produto e do serviço, da qual trata o presente trabalho, é disciplinada na Seção II, arts. 12 a 17, aqui se encontram os vícios ou defeitos de segurança do produto ou serviço que ocorre quando a utilização de um produto ou serviço pode vir a adicionar riscos a segurança do consumidor ou de terceiros; como por exemplo, a compra de uma vacina para imunização de eqüinos quando da sua aplicação causa a morte dos mesmos. Nessa hipótese, o vício geralmente é oculto gerando danos durante a sua utilização e fruição, o que se convencionou chamar de "acidente de consumo".

Destarte, no curso da História, a responsabilidade subjetiva ou teoria clássica, consagrada pelo Código Napoleônico, fundada no conceito de culpa e exteriorizada nas modalidades de negligência, imprudência e imperícia, na qual a vítima tem que provar a culpa do empresário foi sofrendo modificações passando por uma fase intermediária traduzida como "presunção de culpa".

Até que a doutrina e os tribunais foram percebendo que, como aduz Cáio Mario

\section{da Silva Pereira $(1994$, p.262),}

especialmente a desigualdade econômica, a capacidade organizacional da empresa, as cautelas do juiz na aferição dos meios de prova trazidos ao processo nem sempre logram convencer da existência da culpa, e em conseqüência a vítima remanesce não indenizada, posto se admita que foi efetivamente lesada. Por um lado o aumento populacional, o crescimento dos eventos danosos, a multiplicação dos acidentes, o número crescente de ações indenizatórias em que a vitima, sem deixar de ser vítima, sucumbe à míngua de elementos probatórios. 
Por outro lado, a rigidez e relativa imobilidade do direito positivo levantando obstáculos à realização da justiça ideal e provocando desequilibro.

Coube ao doutrinador Luiz Gastão Paes de Barros Leães a primazia de discorrer sobre a responsabilidade do fabricante pelo fato do produto. Essa terminologia "surgiu em recente literatura e vem identificando hipóteses de responsabilidade do empresário pela fabricação e distribuição de bens defeituosos no mercado causadores de dano a integridade psicofísica das vítimas, ou ao seu patrimônio. Aduz, ainda, que para a configuração dessa responsabilidade, é irrelevante sejam as vítimas parte da cadeia de circulação jurídica do produto, mantenham com este uma mera relação de fato decorrente do uso ou do consumo, ou simplesmente tenham se exposto aos efeitos do seu campo de periculosidade.” ( Leães apud Stoco, 2004, p.443).

Diante dessa evolução o Código de Defesa do Consumidor consagrou a responsabilidade objetiva nos arts. 12 e 14 inovando. Assim, respondem independentemente de culpa o fabricante, o produtor, o construtor e o importador pela reparação dos danos causados aos consumidores decorrentes de projeto, fabricação, construção, montagem, formulas, manipulação, apresentação e acondicionamento de seus produtos, bem como por informações insuficientes ou inadequadas sobre sua utilização e riscos.

Essa responsabilidade objetiva funda-se na teoria do risco para a qual são irrelevantes os elementos da teoria clássica, quais sejam: antijuridicidade, culpa, dano, imputabilidade, nexo de causalidade entre a conduta danosa e o dano. O que importa é verificar se houve o evento e se dele emanou o prejuízo, sem se cogitar se houve culpa, em sentido latu, por parte do agente.

Destarte, a responsabilidade por danos, no Código de Defesa do Consumidor, provém de um vício no produto ou no serviço que alcança o consumidor e terceiros, vítimas do evento, e que tem como pressupostos: "defeito do produto; eventus damini; relação de causalidade entre o defeito e o evento danoso". ${ }^{6}$ Alia-se a isso a inversão do ônus da prova. Se antes a vítima tinha o dever de provar a culpa do empresário, agora é este quem tem de provar que não é o responsável pelo dano, o que será abordado no próximo tópico.

\subsection{Da responsabilidade pelo fato do produto}

\footnotetext{
${ }^{6}$ DENARI, Zelmo. Código Brasileiro de Defesa do Consumidor. 6.ed. Rio de Janeiro: Forense Universitária, 1999. p. 154.
} 
O Código do Consumidor trata da "responsabilidade pelo fato do produto e do serviço" nos arts. 12 a 17. Como já mencionado no tópico anterior, o legislador ao discorrer no art. $12^{\circ}$ que respondem independentemente de culpa o fabricante, o fornecedor, produtor e o importador pela reparação dos danos causados ao consumidor, adota no código a responsabilidade objetiva. E como se observa, exclui o comerciante, o qual será responsabilizado em via secundária, já que sua responsabilidade é subsidiária $\left(\operatorname{art.} 13^{\circ}\right)$.

Quanto aos "defeitos decorrentes de projeto, fabricação, construção, montagem, fórmulas, manipulação, apresentação ou acondicionamento, bem como por informações insuficientes ou inadequadas sobre sua utilização e riscos" $\left(\operatorname{art} .12^{\circ}\right)$ a doutrina costuma dividi-los em três modalidades. Na primeira tem-se o chamado defeito de concepção ou criação, nesse caso os vícios podem ser resultantes de erro no projeto, ou por uso de produtos inadequados ou nocivos à saúde. O defeito atinge todos os produtos da mesma série, podendo se ter como exemplo o caso dos medicamentos defeituosos que são retirados do mercado de consumo. Conclui-se, portanto, na aceitação por parte dos fabricantes, da teoria do risco criado. Na segunda modalidade estão os defeitos de produção ou de fabricação que resultam de falhas, mecânica ou manual, no processo produtivo e assinalam sua inviabilidade. Os vícios aparecem em alguns exemplares refletindo o controle de qualidade dos produtos. Por último, os defeitos de informação ou de comercialização, os quais decorrem de informações vinculadas ao produto que são inadequadas ou insuficientes sobre sua utilização e riscos.

As duas primeiras categorias de vícios configuram os defeitos intrínsecos e a última os vícios extrínsecos, tendo em vista que estas dizem respeito às informações que acompanham o produto, externamente, como os rótulos, bulas, embalagens, publicidade, etc.

Há que se ressalvar, como bem assevera o doutrinador Rui Stoco (2002, p.449), que a periculosidade inerente ao produto não configura um defeito do mesmo. Um veneno de rato, por exemplo, é eficaz quando satisfaz o fim a que se destina. A "periculosidade é da sua essência" e, por isso, não configura defeito do produto. Com isso, o fornecedor somente poderá ser responsabilizado caso deixe de fazer, devidamente, as advertências necessárias quanto à periculosidade, utilização, conservação do produto, efeitos colaterais (no caso dos medicamentos) entre outros; assim, ele não responderá por vícios intrínsecos, mas sim pelos defeitos extrínsecos. 
O parágrafo único do art. $12^{\circ}$ define como defeituoso aquele produto que não dispõe da segurança que dele razoavelmente se espera, entendendo-se nesse contexto, o uso e consumo do produto, bem como sua utilização, segundo determinadas circunstâncias. A primeira delas está no ins. I, qual seja a "sua apresentação", assim, refere-se aqui aos defeitos extrínsecos já comentados.

O "uso e os riscos que razoavelmente se esperam" é expresso no inc. II. Isso significa que quando o fornecedor anuncia a utilidade, a qualidade ou os riscos que possui o bem, este deve contê-los de modo que sirva ao que efetivamente se propõe. Assim, se o produto oferecer mais riscos que o divulgado ou não tiver a qualidade que é divulgada, responderá o fornecedor pelos possíveis danos e frustrações causados ao consumidor.

Por fim, "a época em que foi colocado em circulação" (inc. III), significando que para concluir se um produto é ou não defeituoso, deve-se levar em conta a época em que foi posto em circulação, inferindo-se que dependendo dessa aferição o fornecedor poderá ou não se isentar da responsabilidade pelos danos causados. Contudo, há divergência doutrinaria quanto a este entendimento. Alguns doutrinadores consideram que o código adotou a teoria dos "riscos de desenvolvimento" proposta pela Comunidade Econômica Européia, a qual é definida como os riscos que os fornecedores correm por vícios que se tornam conhecidos apenas com o desenvolvimento tecnológico posteriores a colocação de serviços e produtos no mercado de consumo. Com isso, consideram que os riscos de desenvolvimento desobrigam os fornecedores pelo fato do produto e do serviço.

A outra corrente doutrinaria, acertadamente, entende que é irrelevante o argumento de que o produtor desconhecia os riscos a eles inerentes baseando-se no conhecimento da época. O que deve ser levado em conta são os conhecimentos da comunidade cientifica daquele momento histórico e não de apenas um fornecedor. $\mathrm{E}$ ainda, conforme Denari (1999, p.164): “quando estão em causa vidas humanas, as eximentes de responsabilidade devem ser recebidas pelo aplicador da norma com muita reserva e parcimônia”.

O legislador preocupou-se também em prevenir o obsoletismo de nosso parque industrial quando, no $\S 2^{\circ}$ do artigo em pauta, discorreu que o fato de haver um novo produto de melhor qualidade no mercado não torna o anterior defeituoso. Do contrário, seria um caos desestimulante para o desenvolvimento científico e tecnológico. 
Apesar de adotar o Código do Consumidor a responsabilidade objetiva, ela não é absoluta e por isso admite excludentes da responsabilidade, as quais estão elencadas, no parágrafo $3^{\circ} \mathrm{e}$ incs. do mesmo artigo:

I- $\quad$ que não colocou o produto no mercado;

II- $\quad$ que embora haja colocado o produto no mercado, o defeito inexiste; ${ }^{7}$

III- a culpa exclusiva do consumidor.

Assim, para eximir-se da responsabilidade pelo farto do produto o fabricante, produtor, construtor ou importador pode provar que não colocaram o produto no mercado de consumo. Inserem-se aqui aqueles casos de falsificação de produtos, roubo ou furto de mercadorias defeituosas estocadas e, portanto, colocadas no mercado sem o consentimento do fornecedor.

Antes do advento do Código do Consumidor, era a vítima quem deveria provar a existência do vício e a culpa do fornecedor; após, com a adoção da inversão do ônus da prova, passou ao fornecedor o ônus de provar, inequivocamente, a inexistia de defeito no produto, já que é presumida a existência do mesmo. Caso ficar provado que o produto não tinha vícios de qualidade quebra-se o nexo de causalidade e exime-se de responsabilidade pelo dano, o fornecedor. Cabem nesse inciso os casos de acidentes de carro quando o fabricante prova que o mesmo não foi provocado por defeitos intrínsecos ou extrínsecos do veículo.

Também pode o fornecedor provar a "culpa exclusiva do consumidor ou de terceiro". Existindo conduta culposa exclusiva desses, inexiste vício do produto e, conseqüentemente, desaparece a relação de causalidade. A doutrina entende que a lei admite apenas como excludente a culpa exclusiva, não se confundindo com a culpa concorrente. Ocorrendo esta e sendo a conduta da vitima inócua para a produção do dano, persiste a responsabilidade integral do fornecedor, posto que é seu o dever de segurança.

Quanto ao terceiro existe divergência no sentido de que se pode o comerciante ser responsabilizado como tal. Herman de Vasconcellos e Beijamin, consoante Denari (1999, p.166), defende o pensamento de que mesmo tendo responsabilidade subsidiária o comerciante faz parte da relação de consumo, não podendo, por isso, o fabricante, o fornecedor ou importador alegar culpa exclusiva do comerciante para não serem responsabilizados pelos danos ocorridos. 
A outra corrente doutrinaria entende que pode o comerciante ser considerado terceiro com o argumento de que sua responsabilidade subsidiaria o diferencia dos responsáveis do art. $12^{\circ}$, caput, e que o mesmo dispositivo não faz distinção, não cabendo ao interprete fazê-la.

Assim, são duas as situações em que esta corrente doutrinaria entende o comerciante como terceiro:

$1^{\circ}$ ) Nos termos do inc. III, nos casos em que ficar demonstrada a exclusividade de sua culpa no evento danoso.

$2^{\circ}$ ) Quando nos termos do art. $13^{\circ}$, o fornecedor ou o produtor não puderem ser identificados (inc. I e II), ou quando os produtos perecíveis não forem conservados de forma adequada ( inc.III). ${ }^{8}$

O caso fortuito ou força maior, excludentes de responsabilidade no Direito Civil não foram expressamente elencados no artigo em comento, contudo, a doutrina dividiuos em dois momentos, cabendo ao juiz analisar o caso concreto. Desse modo, se o defeito surgiu, por caso fortuito ou força maior, no momento da concepção ou durante sua fabricação o fortuito é chamado interno e não afasta a responsabilidade do fornecedor pelos danos causados, pois este tem o dever de garantir a qualidade e segurança do produto.

Diversamente, se o fato ocorrer depois de colocado o produto no mercado de consumo tem-se o fortuito externo, o qual elimina o nexo de causalidade exonerando o dever de indenizar do fornecedor. Nesse caso o defeito do produto se quer existe e o evento causador do dano deve ser imprevisível.

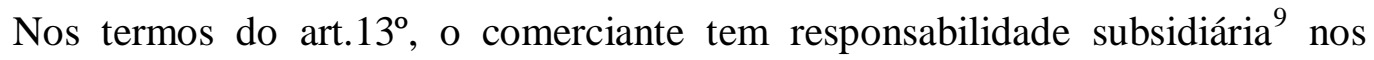
acidentes de consumo quando "o fabricante, o construtor, o produtor ou o importador não puderem ser identificados" e, de maneira semelhante, quando o produto não tiver a identificação clara dos fornecedores acima referidos. Desses casos, a mais comum ocorre quando o comerciante não conserva de forma adequada os produtos perecíveis.

Da dicção do artigo anteriormente citado, quando o legislador refere que o “comerciante é igualmente responsável nos termos do artigo anterior", infere-se que o fato do comerciante responder subsidiariamente nos casos mencionados não afasta do mesmo a responsabilidade objetiva pelos acidentes de consumo. Assim, ele atua como "garante" substituindo os outros partícipes da relação de consumo e respondendo

\footnotetext{
${ }^{8}$ DENARI, Zelmo. Código Brasileiro de Defesa do Consumidor. 6. ed. Rio de Janeiro: Forense Universitária, 1999. p. 167.

${ }^{9}$ Apelação Cível e Recurso Adesivo n. 70006375802, Tribunal de Justiça do RS, julgado em 27/05/2004.
} 
objetivamente quando os mesmos não puderem ser identificados ou encontrados. Vale lembrar que, assim como os comerciantes, os coobrigados do art. $12^{\circ}$, caput, têm direito de regresso contra os demais co-responsáveis na causação do dano.

\subsection{Da responsabilidade pelo fato do serviço}

Da mesma forma que os entes elencados no art. 12, caput, também o fornecedor de serviços, em conformidade com o art. $14^{\circ}$, são responsabilizados objetivamente, ou seja, independente de culpa, pelos danos causados aos consumidores por prestação de serviços defeituosos, bem como pelas informações insuficientes ou inadequadas sobre sua fruição e riscos, tendo como pressupostos: defeito do serviço, evento danoso, relação de causalidade entre o defeito do serviço e o dano. Diante disso, cabem aos fornecedores de serviços as mesmas considerações anteriormente feitas.

Nos termos do art. $14^{\circ}, \S 1^{\circ}$ e incisos, um serviço é considerado defeituoso quando não oferece a segurança e a qualidade que razoavelmente dele se espera levando-se em conta "o modo de seu fornecimento" ( inc. I), assim entendido quanto a sua apresentação ao público consumidor, via publicidade, propaganda ${ }^{10}$, etc.; o "resultado" ( inc.II) que se espera do serviço prestado; os "riscos" (inc.II) que quando de sua fruição não podem ser maiores que o razoavelmente expectado; bem como a “época em que foi fornecido" (inc.III),

Da mesma sorte que o produto, o serviço não é considerado defeituoso pelo fato de surgirem novas técnicas, devendo ser levada em conta à técnica atual no momento da prestação do serviço. Bem assim, exime-se da responsabilidade pelos danos causados o fornecedor que provar que não existe defeito no serviço prestado, ou a culpa exclusiva do consumidor ou de terceiro. O caso fortuito e a forca maior atuam como excludentes da responsabilidade do prestador de serviços sem se questionar se o fato ocorrera durante ou após a prestação dos serviços. Por isso, pode um hospital não ser responsabilizado pelo fato do serviço, alegando que antes ou durante o ato operatório houve corte do fornecimento de energia elétrica. Contudo, não se admite caso fortuito ou forca maior como excludentes de responsabilidade antes da prestação dos serviços. ${ }^{11}$

São considerados fornecedores de serviços respondendo, nos termos do art. $14^{\circ}$ e segundo a responsabilidade objetiva adotada pelo código do consumidor, pelos danos causados pela prestação de seus serviços não somente as empresas privadas, mas

\footnotetext{
${ }^{10}$ Apelação Cível n.7000119768, Nova Câmara Cível, Tribunal de Justiça do RS, relator: Rejane Maria Dias de Castro Bins, julgado em 06/10/1999. ${ }^{11}$ DENARI, Zelmo. Código Brasileiro de Defesa do Consumidor. 6.ed. Rio de Janeiro: Forense Universitária, 1999. p. 172.
} 
também os órgãos públicos, suas concessionárias, permissionária ou outras formas de empreendimentos, segundo se abstrai do art. $22^{\circ}$, caput e $\S$ único do CDC. Sendo dever destas a prestação de serviços adequados, eficientes, seguros e quando essenciais, contínuos.

No que tange aos profissionais liberais como médicos e advogados, o $\S 4^{\circ}$ do art. $14^{\circ}$ atribuiu-lhes responsabilidade subjetiva, entretanto, a Lei não deixa de caracterizar essa prestação de serviços como de consumo sendo válidos todos os demais princípios do Código de Defesa do Consumidor. E isso não deixa dúvidas quando se leva em conta a atuação desses profissionais na sociedade contemporânea, onde cada vez mais eles estão deixando de atuar individualmente para formarem associações, as quais certamente são fornecedoras de serviços, sem deixarem de ser da mesma forma quando atuam individualmente. Tendo em vista que de um lado está o cidadão (consumidor) que busca a prestação de serviços desses profissionais liberais, e de outro o profissional (fornecedor) que coloca no mercado os seus serviços, caracterizando, dessa forma, a relação de consumo.

Ainda, a contratação dos serviços desses profissionais é baseada na relação de confiança entre os mesmos e seus clientes, e é por essa razão que serão responsabilizados quando ficar provado que agiram com culpa, em qualquer das suas modalidades (negligência, imprudência e imperícia). No entanto, permanece a possibilidade da aplicação do princípio da inversão do ônus da prova, ficando a cargo do profissional provar que não agiu com culpa.

Não raro os danos causados pelos defeitos intrínsecos ou extrínsecos dos produtos e serviços (vícios de qualidade) afetam terceiros, os quais são parte legítima para ingressar com pedido de reparação de danos, como se infere da dicção do art. $17^{\circ}$, o qual equipara aos consumidores todas as vítimas do evento danoso. Um bom exemplo é o que ocorre quando da contaminação dos rios pelos agrotóxicos e fertilizantes utilizados nas lavouras, os danos causados podem atingir uma quantidade por vezes indeterminada de pessoas, além dos danos provocados ao meio ambiente que diz respeito a todo cidadão.

Destarte, na Seção II, o Código de Defesa do Consumidor busca tutelar o pólo vulnerável da relação de consumo, bem como assegurar o dever dos fornecedores de ofertarem ao público consumidor produtos e serviços que satisfaçam os requisitos de segurança e qualidade, cumprindo o fim a que se destinam. Para tanto, a legislação lhes atribui a responsabilidade objetiva tornado do próprio interesse dos mesmos à satisfação 
do consumidor, não somente para que o produto ou serviço tenha uma boa aceitação e se fortaleça no mercado, mas também a fim de evitar indenizações por vícios de qualidade, o que diminuiria o prestigio desses bens e causaria um dispêndio econômico não esperado para os fornecedores.

\section{CONSIDERAÇÕES FINAIS:}

Com este trabalho, infere-se que o Direito deve estar sempre em desenvolvimento a fim de acompanhar a evolução da sociedade. Desse modo, a adoção da responsabilidade objetiva por parte do legislador do Código de Defesa do Consumidor demonstra o avanço deste diploma quando comparado a outros institutos, inclusive de ordem internacional. Como demonstra o art. 931 do Código Civil de 2002, o qual nasceu superado e anacrônico, sendo dispensada a sua redação.

O Código de Defesa do Consumidor foi positivado a fim de prevenir e reparar os danos causados aos consumidores finais que muitas vezes tinham seus interesses de reparação frustrados devido ao fato de em muitos casos a prova da culpa do fornecedor ser inviável para eles. Destarte, a adoção da responsabilidade objetiva dos fornecedores de produtos e serviços e a conseqüente tutela do consumidor vulnerável têm a finalidade de incentivar a qualificação dos bens e serviços postos no mercado de consumo, bem como garantir o respeito à dignidade, saúde e segurança do público consumidor.

\section{REFERENCIAS BIBLIOGRAFICAS:} GRINOVER, Ada Pellegrini. et al. Código Brasileiro de Defesa do Consumidor: Comentado Pelos Autores do Ante Projeto. 6.ed. Rio de Janeiro: Forense Universitária, 1999.

PEREIRA, Caio Mario da Silva, Responsabilidade Civil, Rio de Janeiro: [s.ed.], 1994. STOCO, Rui, Tratado de Responsabilidade Civil. 6.ed. São Paulo: Revista dos Tribunais, 2004.

VENOSA, Sílvio de Salvo, Responsabilidade Civil. 2.ed. São Paulo: Atlas S., 2002. http://www.tj.gov.br http://www.uj.com.br 